COMMENT. Cysticercal cysts evolve through 4 stages: vesicular with living larva, colloidal stage with degenerate larva, granulonodular stage with thickened cyst membrane, and calcification stage. Only cysts in the vesicular and colloidal stages contain the larvae and are amenable to anticysticercal treatment. Cysticercosis, infection with the larval form of Taenia solium, is the most common preventable cause of epilepsy in the developing world (Coyle CM, et al. PLoS Negl Trop Dis 2012;6(5):e1500).

\title{
ENCEPHALITIS
}

\section{ANTI-N-METHYL-D-ASPARTATE RECEPTOR ENCEPHALITIS}

Investigators at Universities of Barcelona, Pennsylvania, Oviedo, and Valencia, and the Spanish NMDAR Encephalitis Work Group report the clinical features of 20 pediatric patients with anti-N-methyl-D-aspartate receptor (NMDAR) encephalitis seen in a single center in Spain in the last 4 years. Median patient age was 13 years (range, 8 months-18 years); 70\% were female. Initial symptoms were neurologic (dyskinesias or seizures) in $12(60 \%)$ and psychiatric in $40 \%$. By one month after disease onset, all had involuntary movements and changes in behavior and speech. All patients received steroids, IV immunoglobulin or plasma exchange, and 7 rituximab or cyclophosphamide. At a median follow-up of 17.5 months, $85 \%$ had substantially recovered, $10 \%$ had moderate or severe deficits, and 1 had died. Three patients had previous episodes compatible with anti-NMDAR encephalitis, and 2 had additional relapses. Ovarian teratoma was identified in 2 patients $(10 \%), 1$ at disease onset and the other one-year later. A novel characteristic EEG pattern ("extreme delta brush") occurred in one 18year-old patient. A 2-year-old patient developed anti-NMDAR as post herpes simplex encephalitis choreoathetosis; her recovery was complicated by a bilateral facial weakness and anarthria (Foix-Chavany-Marie syndrome). (Armangue T, Titulaer MJ, Malaga I, et al. Pediatric anti-N-methyl-D-aspartate receptor encephalitis - Clinical analysis and novel findings in a series of 20 patients. J Pediatr 2013 Apr;162(4):850-856.e2). (Reprint requests: Josep Dalmau MD, PhD, E-mail: Josep.dalmau@uphs.upenn.edu).

COMMENT. Since the initial description of NMDAR encephalitis (Dalmau J, et al. Ann Neurol 2007 Jan;61(1):25-36), and in children (Florance NR, et al. Ann Neurol 2009 Jul;66(1):11-8), this encephalitis has been reported frequently as single case histories, small series, and in one large series of 500 patients (Titulaer MJ, et al. Neurology 2012 Apr; 78(Meeting Abstracts 1): PL01.001). The present series in children adds to our experience with this intriguing disorder and increases our awareness of the presenting symptoms and diagnosis. The rare link between NMDAR encephalitis and post herpes simplex encephalitis choreoathetosis, and the etiologic significance of ovarian teratoma require further study. The "delta brush" EEG pattern in one patient, previously described in $30 \%$ of an adult cohort, may be unique to NMDAR encephalitis and correlates with disease severity (Schmitt SE, et al. Neurology 2012 Sep 11;79(11):1094-1100). 